\title{
Guia de identificação dos ninhos de vespas sociais (Hymenoptera, Vespidae, Polistinae) na Reserva Ducke, Manaus, Amazonas, Brasil
}

\author{
Alexandre Somavilla ${ }^{1,4}$, Marcio Luiz de Oliveira ${ }^{2} \&$ Orlando Tobias Silveira ${ }^{3}$
}

\begin{abstract}
'Programa de Pós Graduação em Entomologia, Instituto Nacional de Pesquisas da Amazônia.
${ }^{2}$ Coordenação de Biodiversidade, Instituto Nacional de Pesquisas da Amazônia, André Araújo, 2936, 96060-001 Manaus-AM, Brasil.

${ }^{3}$ Coordenação de Zoologia, Museu Paraense Emílio Goeldi, Av. Perimetral s/n, Campus de Pesquisas, 66040-170 Belém-PA, Brasil.

${ }^{4}$ Autor para correspondência: Alexandre Somavilla, alexandre.s@hotmail.com
\end{abstract}

\begin{abstract}
Identification guide for nests of social wasps (Hymenoptera: Vespidae: Polistinae) in Reserva Ducke, Manaus, Amazonas, Brazil. Nests of social wasps are composed mainly out of plant material. Although there are some studies about the social wasp fauna in the Amazon region, there is no work exclusively about these wasps' nests. Also, there are few catalogued nests in biological collections, because of their fragility and difficult conservation. The purpose of this study was to evaluate the kinds of nests found at "Reserva Ducke", compiling information about them and developing a key to identify the nests of each genera. The nests were actively collected in tracks of the "Programa de Pesquisa em Biodiversidade" plot; areas such as "igarapés" margins, base camp's surroundings and buildings at the reserve headquarters were also explored. All the nests were photographed and their precise location was obtained by GPS. Thirty-nine wasp's nests from 17 species of Polistinae were recorded: Agelaia constructor, A. pallipes, Angiopolybia pallens, Apoica pallens, Metapolybia unilineata, Mischocyttarus lecointei, M. saturatus, Polybia bistriata, P. dimidiata, P. jurinei, P. liliacea, P. occidentalis, P. procellosa, P. rejecta, Protopolybia bituberculata, P. chartergoides and Synoeca virginea. Five uninhabited nests of Mischocyttarus, Polybia and Polistes were collected.
\end{abstract}

KEYWORDS. Nesting habits; paper-wasps; Polistinae; terra firme dense ombrophylous forest.

\begin{abstract}
RESUMO. Guia de identificação dos ninhos de vespas sociais (Hymenoptera, Vespidae, Polistinae) na Reserva Ducke, Manaus, Amazonas, Brasil. Vespidae sociais utilizam principalmente material vegetal para a elaboração de seus ninhos. Embora existam alguns estudos referentes à fauna de vespas na região Amazônica, nenhum trabalho trata exclusivamente dos ninhos. Além disso, nas coleções biológicas poucos são os ninhos tombados, devido principalmente à fragilidade e difícil conservação dos mesmos. O objetivo desse trabalho foi o conhecimento de alguns ninhos encontrados na Reserva Ducke, apresentando informações a respeito dos mesmos e uma chave de identificação dos gêneros. Os ninhos foram coletados através da busca direta, percorrendo os transectos da grade do Programa de Pesquisa em Biodiversidade; locais como margens de igarapés, bordas de acampamentos e construções na sede da reserva também foram explorados. Para todos os ninhos obteve-se o registro fotográfico e a localização exata por GPS. Foram registrados 39 ninhos de vespas sociais alocados em 17 espécies de Polistinae: Agelaia constructor, A. pallipes, Angiopolybia pallens, Apoica pallens, Metapolybia unilineata, Mischocyttarus lecointei, M. saturatus, Polybia bistriata, P. dimidiata, P. jurinei, P. liliacea, P. occidentalis, P. procellosa, P. rejecta, Protopolybia bituberculata, P. chartergoides e Synoeca virginea. Cinco ninhos desabitados de Mischocyttarus, Polybia e Polistes também foram coletados.
\end{abstract}

PALAVRAS-CHAVE. Floresta ombrófila densa de terra firme; hábito de nidificação; marimbondos; Polistinae.

Vespidae possui dois modos distintos quanto ao material utilizado na construção dos seus ninhos. As vespas de comportamento solitário, como Eumeninae e Masarinae, com exceção de algumas espécies de Zethus Fabricius, elaboram seus ninhos exclusivamente de barro ou em cavidades. As vespas sociais utilizam principalmente material vegetal, e elaboram os ninhos de maneira independente (Polistini, Mischocyttarini e alguns Ropalidiini) ou por enxameamento (maioria dos Ropalidiini e Epiponini) (Wenzel 1998; Carpenter \& Marques 2001).

Em Polistinae os ninhos são muito diversos, variando desde um único favo descoberto, com cerca de $5 \mathrm{~cm}$ de diâmetro e poucas dezenas de células de cria, até ninhos com mais de $50 \mathrm{~cm}$ de comprimento, que podem permanecer ativos por muitos anos, com várias camadas de células de cria sobrepostas abrigando milhões de células e envoltos por uma "capa", denominada de invólucro (Carpenter \& Marques 2001; Souza \& Zanuncio, 2012). Esses ninhos podem ser constituídos pelos mais diversos tipos de materiais, como fibras vegetais e tricomas de plantas, que são macerados e misturados com água e, em alguns casos, com secreção glandular e barro. Por utilizarem material vegetal para a construção do ninho, são popularmente conhecidas como "paper wasps" (Jeanne 1975; Wenzel 1998).

Os ninhos podem ser construídos na superfície abaxial de folhas, em construções humanas (espécies de Polistes Latreille, Mischocyttarus de Saussure, Leipomeles Moebius, Apoica Lepeletier, algumas espécies de Polybia Lepeletier), diretamente sobre o tronco de uma árvore (Metapolybia Ducke, Synoeca de Saussure), presos em ramos vegetais (Brachygastra Perty, Polybia Lepeletier), escondidos em cavidades, como por exemplo, buracos em troncos de árvores 
ou no solo (algumas espécies de Agelaia Lepeletier e Polybia Lepeletier) (Carpenter \& Marques 2001).

A diversidade de formas e a complexidade arquitetônica dos ninhos são tantas que alguns detalhes estruturais têm sido usados na elaboração de chaves de identificação em nível de gênero ou em trabalhos tratando a diversidade de ninhos de vespas em alguns locais, além de ser útil na obtenção de caracteres comportamentais para análises filogenéticas (Wenzel 1998; Arab et al. 2003; Nascimento et al. 2008; Prezoto \& Clemente 2010; Souza \& Zanuncio 2012).

A formação de novos ninhos ocorre por enxameamento ou fundação independente (Wenzel 1998). No primeiro processo, um enxame com várias rainhas e centenas ou milhares de operárias deixa a colônia original e busca um local adequado para instalar o novo ninho. $\mathrm{Na}$ fundação independente, a nova colônia é iniciada por uma ou poucas vespas, dentre as quais uma assume o papel de rainha ou um grupo com poucos indivíduos subordinados pela anterior (Wenzel 1998; Prezoto et al. 2008). Em ambos os casos, a fêmea responsável pela reprodução alimenta as larvas, utilizando pólen e néctar regurgitado e proteína animal (Carpenter \& Marques 2001).

Grande parte do entendimento da evolução da socialidade provém de estudos comportamentais e biológicos das vespas e outros insetos sociais e de estruturas referentes à sua nidificação (Wenzel 1998; Nascimento et al. 2008). A variação da arquitetura do ninho está relacionada com a espécie. Em alguns casos, a diferença encontrada no ninho é mais notável que a variação morfológica da vespa. Algumas espécies foram ordenadas inicialmente, principalmente em gêneros, baseando-se nos ninhos. Alguns tratamentos demonstram que arquitetura, associada ao comportamento de construção do ninho, são particularmente úteis para traçar linhagens filogenéticas em muitos animais (Wenzel 1992).

Objetivou-se registrar os ninhos de vespas sociais encontrados na Reserva Ducke, disponibilizando uma chave de identificação genérica e comentários a respeito dos ninhos e fotografias dos mesmos. Uma chave é oferecida como uma alternativa que poderá ser útil aos especialistas e amadores que têm interesse em conhecer o complexo sistema que envolve a comunidade de vespas e seus ninhos.

\section{MATERIAL E MÉTODOS}

Área de trabalho. A área de coleta foi a Reserva Ducke, com área total de aproximadamente $100 \mathrm{~km}^{2}$ de floresta ombrófila densa úmida de terra firme, e está localizada na rodovia AM 010, $\mathrm{km} \mathrm{26,} \mathrm{nas} \mathrm{proximidades} \mathrm{de} \mathrm{Manaus,} \mathrm{Ama-}$ zonas, Brasil $\left(02^{\circ} 55^{\prime}\right.$ a $03^{\circ} 01^{\prime} \mathrm{S}$ e $59^{\circ} 53^{\prime}$ a $\left.59^{\circ} 59,5^{\prime} \mathrm{W}\right)$ (Baccaro et al. 2008). O clima da reserva é classificado como tropical úmido, com umidade relativa média anual de cerca de $80 \%$ e precipitação anual média de 1.750 a $2.500 \mathrm{~mm}$, sendo os meses mais chuvosos entre novembro a maio e os de menor pluviosidade entre junho e outubro. A temperatura média anual é de $26^{\circ} \mathrm{C}$ existindo pouca variação térmica durante o ano (Ribeiro \& Adis 1984).
Toda a reserva está coberta pela floresta ombrófila densa em planície de baixa altitude, com dossel bastante fechado e sub-bosque com pouca luminosidade, caracterizado pela abundância de palmeiras. A flora é extremamente diversificada, com aproximadamente 1.000 espécies de árvores com 30 a 35 metros e algumas poucas emergentes alcançando 45 a 50 metros (Ribeiro et al. 1999).

Coleta dos ninhos de vespas. Os ninhos foram coletados na Reserva entre os meses de agosto e outubro 2010 e em abril de 2011 através da busca ativa, numa grade de $5 \times 5 \mathrm{~km}$, do Projeto de Pesquisa em Biodiversidade (PPBio), cujo interior é cortado por dois conjuntos perpendiculares de trilhas com extensão de $5 \mathrm{~km}$. As trilhas se entrecruzam em intervalos de $1.000 \mathrm{~m}$, conferindo ao conjunto um formato de grade. Além disso, algumas trilhas e margens de igarapés e ambientes antropizados, como bordas dos acampamentos e construções nas proximidades da sede da reserva, também foram vistoriados.

Os ninhos até $20 \mathrm{~cm}$ foram coletados utilizando sacos plásticos resistentes ou potes de plásticos, contendo dentro algodão embebido em acetato de etila. Após a morte dos vespídeos, estes eram acondicionados em vidros, enquanto os ninhos eram depositados em caixas de isopor, para não serem danificados durante o transporte. Quando o ninho possuía dimensões maiores, apenas alguns indivíduos foram coletados.

Todos os ninhos e seus os respectivos habitantes estão depositados na Coleção de Invertebrados do Instituto Nacional de Pesquisas da Amazônia (INPA). As vespas coletadas foram identificadas por espécie utilizando-se chaves dicotômicas disponíveis em bibliografias especializadas, como Richards (1978) e Carpenter \& Marques (2001) e por comparação com material já depositado. Os ninhos foram classificados de acordo com seus formatos utilizando-se a classificação criada por $\mathrm{H}$. de Saussure (1853) e reestruturado por Richards \& Richards (1951) (Carpenter \& Marques 2001):

- Ninho stelocítaros (de Saussure): um ou mais favos prendem-se ao substrato ou ao favo precedente por meio de pedicelos ou pilares.

Stelocítaros gimnódomos: não possui invólucro e comumente apenas um favo é construído; se mais de um favo então o ninho encontra-se em local bem protegido como ocos de árvores;

Stelocítaro captódomo: um invólucro protetor ocorre em torno dos favos e existem diversas variações estruturais em ninhos deste tipo.

- Ninho astelocítaro (Richards \& Richards): contém um único favo, sendo as células fixadas diretamente ao substrato. Um invólucro em forma de cúpula cobre todo o ninho e o orifício de entrado geralmente é situado na parte inferior.

- Ninho fragmocítaros (de Saussure): o favo inicial é largamente fixado ao substrato e um invólucro é construído ao redor e em contato com as laterais dos favos.

Elaboração da chave para os ninhos de acordo com os respectivos gêneros. Na chave para os ninhos das vespas, de acordo com o gênero, constam características básicas da 
morfologia externa dos ninhos e é uma adaptação do trabalho de Wenzel (1998), para os ninhos de vespas sociais da região neotropical. Os principais caracteres utilizados na elaboração desta chave foram o material utilizado na construção do ninho, o local da nidificação, a presença ou ausência de um invólucro, o método de fixação do ninho (ausência ou presença de pedicelo e sua posição), a posição da entrada do ninho, o tamanho das células de cria e a presença de camadas no ninho, entre outros (Fig. 1). O tamanho do ninho também pode ser um critério útil na caracterização, porém podem existir disparidades nas colônias jovens. Dados sobre as distribuições geográficas das espécies seguiram o formado adotado por Zanella et al. (2000).

\section{RESULTADOS E DISCUSSÃO}

Foram registrados 39 ninhos de vespas para a Reserva Ducke, sendo um de Agelaia constructor (de Saussure, 1854), A. pallipes (Oliver, 1791) (1), Angiopolybia pallens (Lepeletier, 1836) (1), Apoica pallens (Fabricius, 1804) (1), Metapolybia unilineata (R. Von Ihering, 1904) (1), Mischocyttarus lecointei (Ducke, 1904) (1), M. saturatus Zikán, 1949 (1), Polybia bistriata (Fabricius, 1804) (8), P. dimidiata Oliver (1792) (1), P. jurinei de Saussure, 1854 (2), P. liliacea (Fabricius, 1804) (1), P. occidentalis (Oliver, 1791) (4), P. procellosa Ducke, 1910 (2), P. rejecta (Fabricius, 1798) (6), Protopolybia bituberculata Silveira \& Carpenter, 1995 (1), P. chartergoides Gribodo, 1891 (1), Synoeca virginea (Fabricius, 1804) (1), além de cinco ninhos desabitados, não determinados especificamente de Mischocyttarus, Polybia e Polistes.

\section{Chave genérica para os ninhos na Reserva Ducke}

1. Ninhos geralmente escondidos em cavidades em troncos de árvores, ou em barrancos (Fig. 2); poucas espécies fazem ninhos expostos e quando exposto sem invólucro e células de cria de tamanho até $4 \mathrm{~mm}$ Agelaia

1'. Ninho totalmente exposto e preso a algum substrato; ninhos expostos com ou sem invólucro e tamanho das células de cria de 1 a 5 mm (Fig. 3) 2

2. Ninho sem invólucro, com as células de cria totalmente expostas (Fig. 4)

2'. Ninho com invólucro, com as células de cria escondidas (Fig. 5)

5

3. Pedicelo ausente (Fig. 6); camada única de células de cria voltadas para baixo, horizontal, amplamente fixado no substrato ou em alguns casos envolto; geralmente o ninho apresenta coloração clara .... Apoica

3'. Pedicelo presente (Fig. 7), podendo ser simples ou múltiplo; composto por apenas uma camada de células de cria; orientação das células variáveis (vertical ou horizontal), encontrado tanto fixo em folhas, em edificações humanas ou outros substratos; ninhos com coloração variável .......... 4

4. Células de cria pequenas (menor que $4 \mathrm{~mm}$ de diâmetro) (Fig. 8); ninho composto de curtas fibras vegetais .........

.. Mischocyttarus

4'. Células de cria maiores que $4 \mathrm{~mm}$ de diâmetro (Fig. 9); ninho composto de fibras longas e lenhosas ....... Polistes

5. Ninhos envolvendo troncos de árvores, ou galhos mais finos (Fig. 10), ou ainda com as células de cria fixas
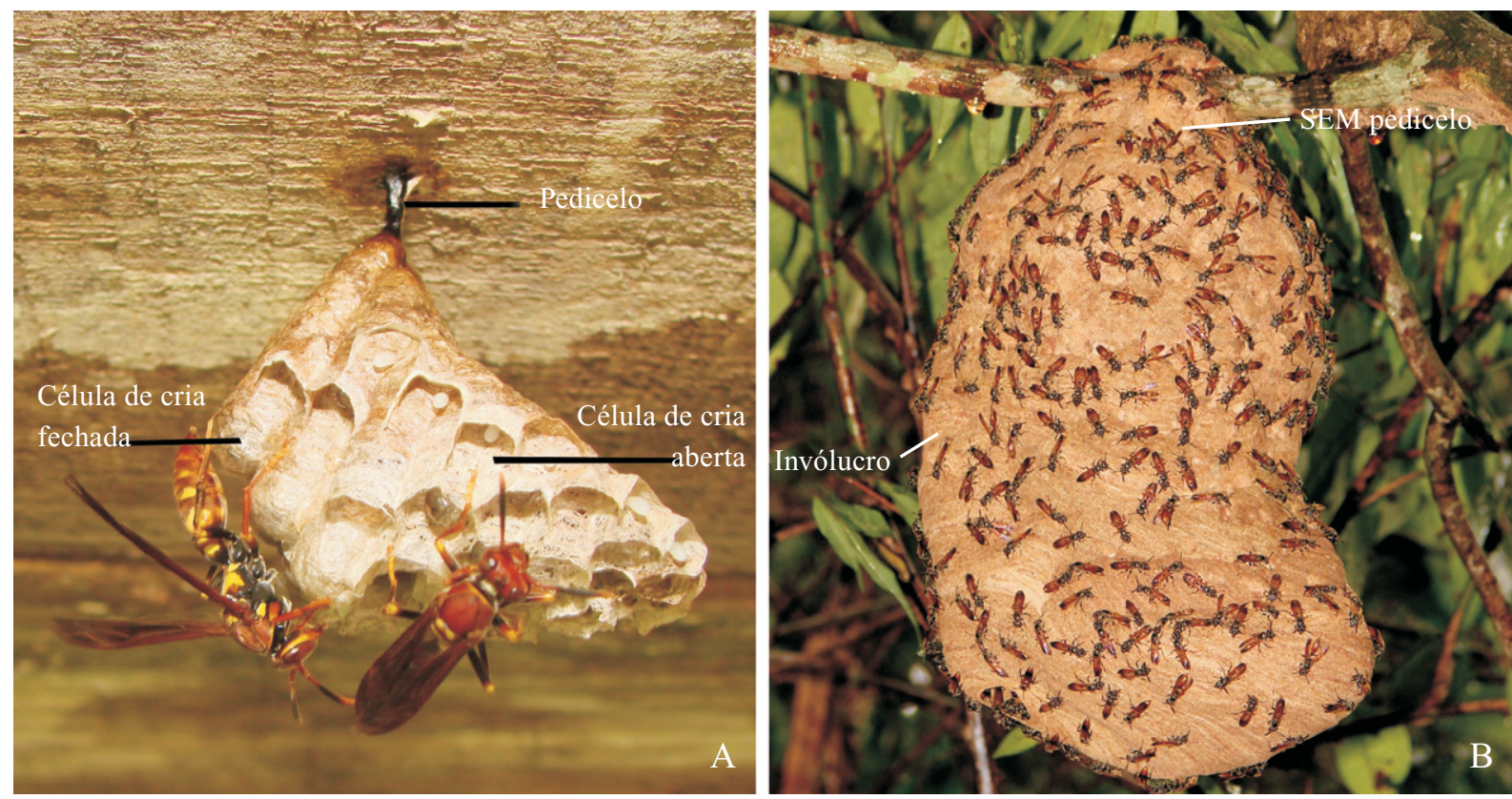

Fig. 1. Características utilizadas na elaboração da chave genérica dos ninhos da Reserva Ducke, Amazonas, Brasil: A- Ninho de Polistes versicolor com pedicelo e células de cria expostas, sem a presença de invólucro para proteção. B- Ninho de Polybia rejecta sem pedicelo e com a presença de invólucro para proteção das células de cria. 
diretamente na superfície do tronco 6

5'. Ninhos fixos em folhas, com um pedicelo (ou pedicelos) amplamente ligado às folhas (Fig. 11) .....

6. Ninho envolvendo tronco de árvore ou galho, com uma única abertura na região inferior; invólucro não resistente, frágil (Fig. 12) Polybia (P. dimidiata)

6'. Ninho com células de cria construídas diretamente na superfície do tronco (Fig. 13); se o ninho envolve tronco de árvore, então com uma única abertura na região superior; invólucro mais resistente

7

7. Ninho com células de cria grandes (maior do que $4 \mathrm{~mm}$ ); invólucro com corrugações transversais (Fig. 14)

Synoeca

7'. Ninho com células de cria pequenas (menores do que 2 $\mathrm{mm}$ ); invólucro sem corrugações transversais (Fig. 15).

Metapolybia

8. Ninho com uma ou mais camadas de células de cria, estas pequenas (1 mm de diâmetro); geralmente fixo em folhas por mais de um pedicelo, estes muito pequenos; invólucro de coloração clara, muito frágil e fino, ou utilizando folhas como função de invólucro colando-as com secreção salivar (Fig. 16) Protopolybia

8'. Ninhos com mais de uma camada de células de cria; estas, pequenas a médias ( $2 \mathrm{~mm}$ de diâmetro); invólucro sempre presente de coloração variada, geralmente mais escura e mais resistente (Fig. 17)

9. Ninho amplamente ligado ao substrato; camadas ligadas uma nas outras através da base, nunca por pedicelos internos; invólucro frágil; formato do ninho geralmente mais arredondado a ovalado (Fig. 18)

Polybia (outras espécies)

9'. Ninho com mais de um pedicelo ligando-o ao substrato, com invólucro único; camadas de células de cria ligadas umas nas outras através de um pedicelo interno; invólucro flexível, longo e ligado ao substrato, a entrada do ninho na parte inferior, em forma de tubo, que é um prolongamento do invólucro (Fig. 19)

Angiopolybia

\section{Caracterização dos ninhos}

\section{Agelaia Lepeletier, 1836}

Os ninhos de Agelaia podem ser arquitetonicamente muito variáveis e encontrados em cavidades ou expostos. Quando em cavidades, estes ninhos podem ser no interior de troncos de árvores, ou no solo; quando expostos, são ninhos simples, com uma ou mais camadas de células de cria, podendo ser com ou sem invólucro para proteção. Os ninhos podem ter desde poucas células (Agelaia flavipennis (Ducke, 1905)),
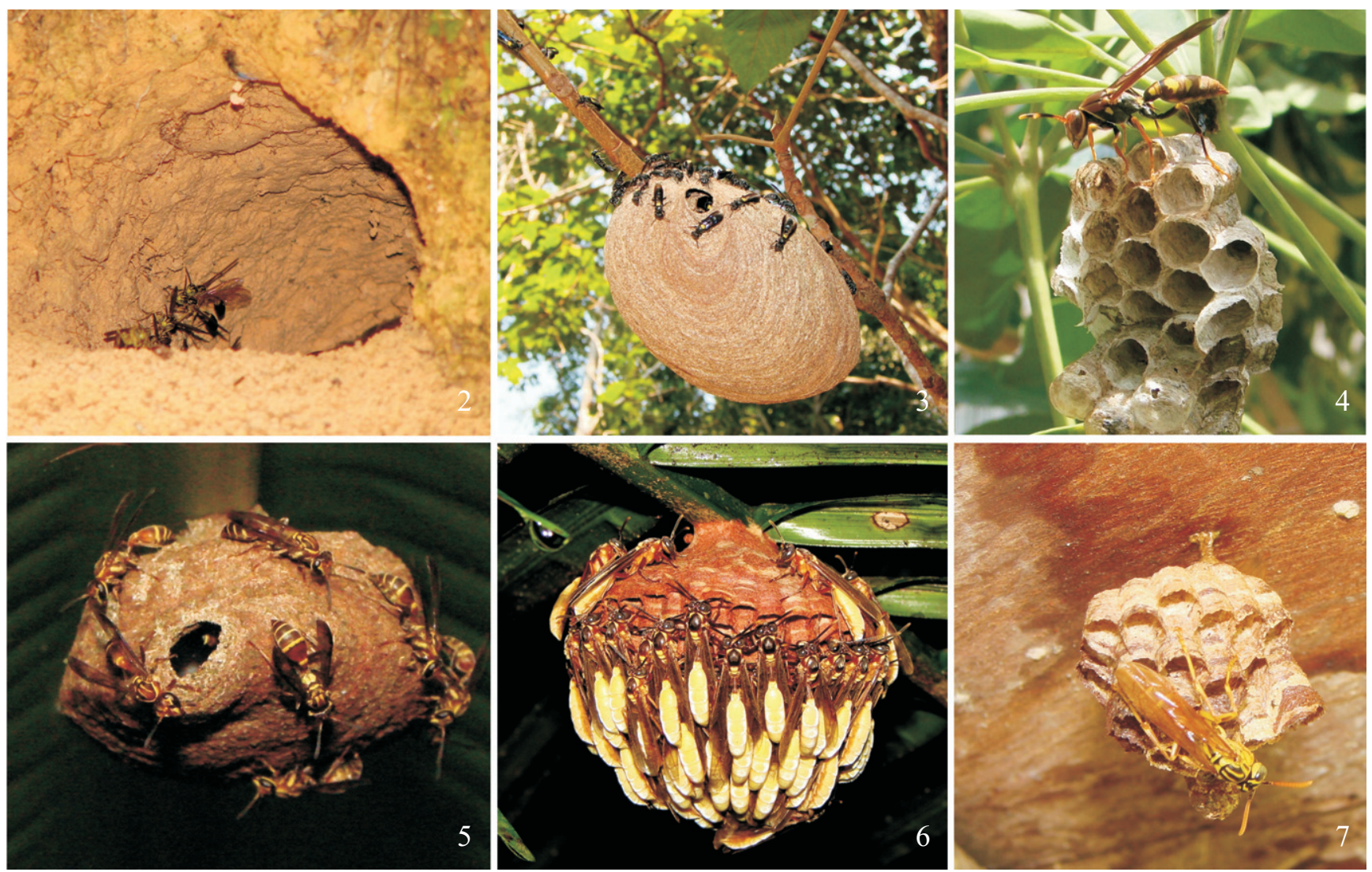

Figs. 2-7. Ninhos de: 2, cavidade onde se encontra o ninho de Agelaia constructor; 3, Polybia jurinei; 4, Polistes versicolor; 5, Polybia bistriata; 6, Apoica pallens; 7 , Mischocyttarus sp. 

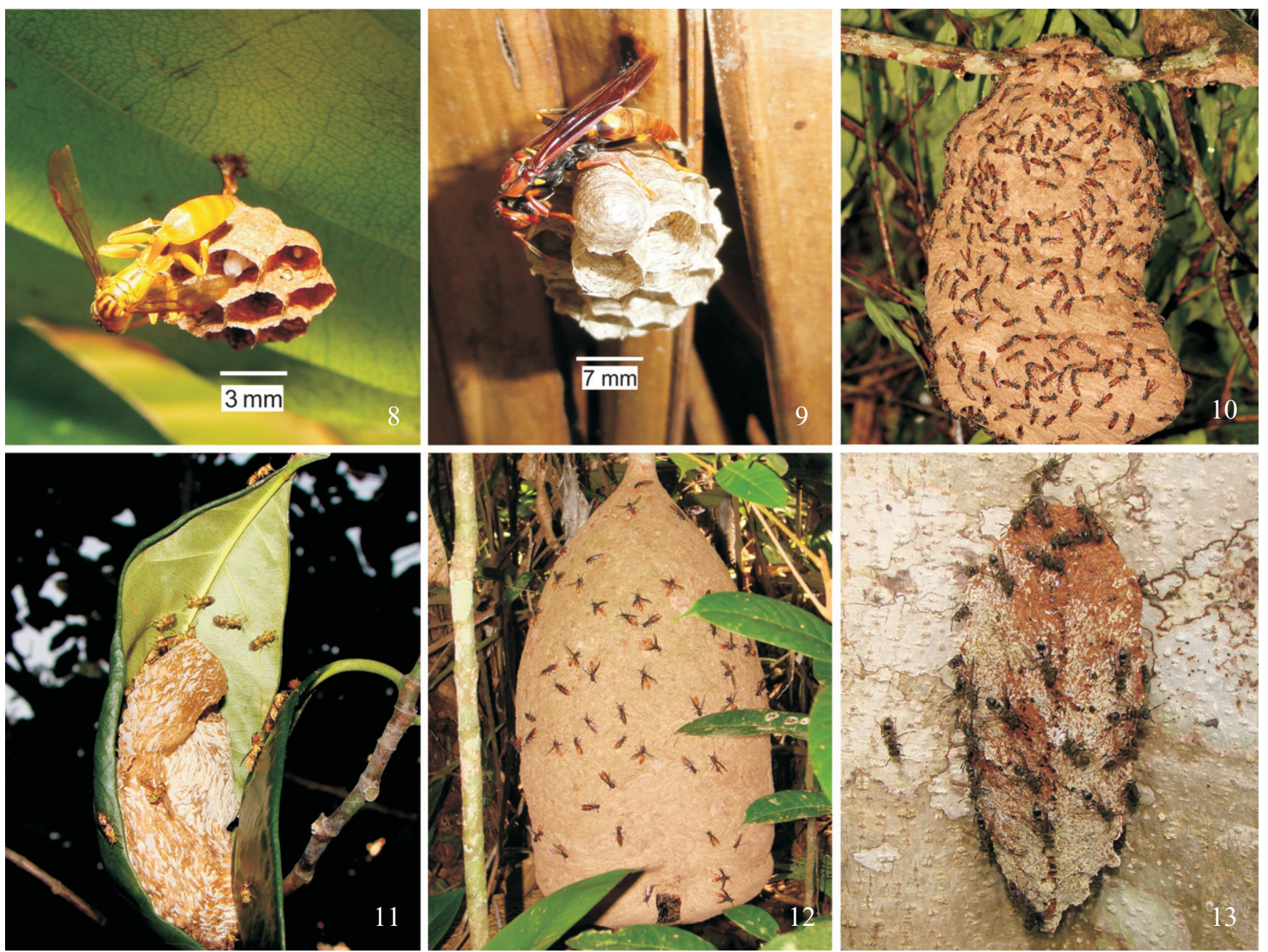

Figs. 8-13. Ninhos de: 8, Mischocyttarus lecontei; 9, Polistes versicolor; 10, Polybia rejecta; 11, Protopolybia bituberculata; 12, Polybia dimidiata; 13, Metapolybia sp.

até milhões de células, sustentadas por múltiplos pedicelos (Agelaia vicina de Saussure, 1854), sendo os ninhos desta espécie os maiores já registrados para vespas sociais (Wenzel 1998; Zucchi et al. 1995; Carpenter \& Marques 2001).

Agelaia constructor (Fig. 2) nidificou em um buraco localizado em barranco, a uma altura de $2 \mathrm{~m}$ do solo, e não foi possível a observação das células de cria utilizadas para oviposição. O ninho possuía uma abertura de aproximadamente $8 \mathrm{~cm}$ de raio, com algumas vespas pousadas, provavelmente responsáveis pela segurança do ninho. Esta espécie possui um comportamento agressivo, diante da menor perturbação, inclusive ferroando instantaneamente os coletores. Ninho do tipo stelocítaro gimnódomo.

Distribuição: Guiana, Brasil (Amapá, Amazonas e Pará).

O ninho de A. pallipes (Fig. 20) estava na cavidade de uma árvore indeterminada de grande porte, com diâmetro de aproximadamente $2 \mathrm{~m}$, sendo que a entrada do ninho ficava a uma altura de 1,20 m, em uma fenda vertical de aproximadamente $15 \mathrm{~cm}$. Uma grande quantidade de vespas protegia esta fenda. Não foi possível a observação das células de cria utilizadas para oviposição. Como a espécie anterior, possui um comportamento agressivo, diante da menor perturbação, inclusive ferroando instantaneamente os coletores. Ninho do tipo stelocítaro gimnódomo.

Distribuição: Costa Rica, Venezuela, Guiana, Suriname, Argentina e Brasil (Amazonas, Pará, Ceará, Maranhão, Mato Grosso, Goiás, Minas Gerais, Rio de Janeiro, São Paulo, Paraná e Rio Grande do Sul).

\section{Angiopolybia Araújo, 1946}

Ninho arbóreo, preso amplamente pela parte superior em folhas. Ocorre pedicelo único em algumas espécies, porém em ninhos maiores estes podem ser múltiplos, mas geralmente com um pedicelo central que liga as camadas de células de cria do ninho. O invólucro constituído de fibras, maior que a dimensão do ninho, em formato de um tubo ou garrafa, contendo na parte inferior uma abertura (Wenzel 1998; Carpenter \& Marques 2001).

O ninho de Angiopolybia pallens (Fig. 19) foi encontrado abandonado em uma árvore de grande porte, estando o ninho fixado em grande quantidade de folhas, a uma altura 
de $2 \mathrm{~m}$. A sustentação ocorria por três pequenos pedicelos, ligados diretamente a essas folhas e galho. O ninho possui $23 \mathrm{~cm}$ de comprimento e $11 \mathrm{~cm}$ de largura, na parte mais larga. O invólucro era maior que a dimensão do ninho, com uma grande abertura na parte inferior. Era composto por 11 camadas, (configuração original), sendo que as mais próximas da base possuíam dimensões maiores que as inferiores, provavelmente devido à idade das mesmas, sendo as superiores elaboradas primeiramente. Apesar de abandonado, foi possível a identificação, uma vez que das três espécies de Angiopolybia registradas para a Reserva Ducke, apenas $A$. pallens possui dimensões tão pequenas que corroboram com o tamanho das células de cria que medem $2 \mathrm{~mm}$. Ninho do tipo stelocítaro caliptódomo.

Distribuição: Trinidad, Colômbia, Venezuela, Guiana, Suriname, Guiana Francesa, Equador, Peru, Bolívia e Brasil (Amapá, Amazonas, Pará, Acre, Maranhão, Pernambuco, Mato Grosso, Bahia, Minas Gerais, Espírito Santo, São Paulo, Paraná e Santa Catarina).

\section{Apoica Lepeletier, 1836}

Ninho arbóreo, frequentemente preso na parte inferior de folhas mais largas e galhos finos. Não possui pedicelo para fixação ao substrato; possui apenas uma única camada de células de cria descoberta. O material utilizado na construção é constituído de pelos (tricomas) e partes de folhas. Possuem a forma de um prato invertido e as células são voltadas para baixo. Geralmente o ninho possui uma coloração clara. São as únicas vespas que possuem um comportamento de forrageio noturno (Wenzel 1998; Carpenter \& Marques 2001).

O ninho de Apoica pallens (Fig. 6) foi encontrado na face abaxial central de uma folha composta da palmeira não determinada, próximo ao solo, a $25 \mathrm{~cm}$ de altura. $\mathrm{O}$ ninho não possui pedicelo, porém, está fortemente ligado ao substrato, deixando-o mais fixo e possivelmente mais seguro de qualquer impacto. Uma grande quantidade de indivíduos se encontrava no ninho, na região das células de cria, sendo que quatro indivíduos estavam sobre estas células, provavelmente sendo responsáveis pela segurança do ninho. As vespas são agressivas quando o ninho é tocado e perturbado. Ninho do tipo stelocítaro gimnódomo.

Distribuição: México, Belize, El Salvador, Costa Rica, Trinidad, Colômbia, Venezuela, Guiana, Suriname, Guiana Francesa, Equador, Peru, Bolívia, Paraguai, Argentina e Brasil (Amapá, Amazonas, Pará, Acre, Mato Grosso, Goiás, Minas Gerais, Rio de Janeiro, São Paulo, Paraná, Santa Catarina, Rio Grande do Sul).

\section{Metapolybia Ducke, 1836}

Ninhos arbóreos ou em edificações humanas, sendo que a maioria das espécies constrói suas células de cria diretamente na superfície de troncos e galhos, e as células de cria são recobertos por um invólucro sem corrugações. Os ninhos são compostos por fibra vegetal e possuem uma única abertura na parte superior ou na região central do ninho. Geralmente as vespas liberam uma secreção de aspecto brilhoso no invólucro do ninho formando uma espécie de janela, que funcionam como uma substância repelente para predadores (Wenzel 1998; Carpenter \& Marques 2001).

O ninho de Metapolybia unilineata (Fig. 15) coletado na Reserva Ducke foi encontrado diretamente numa parede de madeira, a uma altura de aproximadamente $3 \mathrm{~m}$, em um dos dormitórios da base central. Possui uma abertura central e alguns indivíduos na parte externa do ninho, responsáveis pela defesa do ninho. Ninho do tipo astelocítaro.

Distribuição: Peru e Brasil (Amazonas).

\section{Polybia Lepeletier, 1836}

Os ninhos de Polybia podem ser arquitetonicamente muito variáveis e são encontrados em cavidades subterrâneas, mas principalmente expostos, na face abaxial de folhas. Não possuem um pedicelo, portanto a base é ligada diretamente no substrato; algumas espécies nidificam contornando o galho ou tronco da árvore com as camadas das células. Possuem um invólucro frágil na maioria das espécies, porém em algumas, devido a utilização de terra, torna-se rígido (Polybia emaciata Lucas, 1879, P. singularis Ducke, 1909, P. spinifex Richards, 1978, P. furnaria R. von Ihering, 1901 e P. richardsi Cooper, 1993). Ninhos com mais de uma camada são comuns, estando a camada inicial largamente fixada ao substrato e com um invólucro protetor em contato com as laterais desta camada de células de cria. Posteriormente são acrescentadas mais camadas pela adição de células na parte inferior do ninho, o qual é expandido. Alguns podem chegar a dezenas de camadas (Polybia dimidiata, P. scutellaris (White, 1841)). Geralmente possuem apenas uma entrada simples e localizada na parte inferior do ninho (Wenzel 1998; Carpenter \& Marques 2001).

Foram encontrados oito ninhos de Polybia bistriata (Fig. 5) na Reserva Ducke, os quais tiveram dimensões pequenas (entre 5 a $8 \mathrm{~cm}$ ), porém com uma grande quantidade de indivíduos (aproximadamente 100). Os ninhos possuem um aspecto arredondado e achatado, invólucro frágil, apenas uma abertura e amplamente fixados na parte abaxial de folhas. Os substratos mais comuns foram frondes de palmeiras do gênero Bactris e folhas de uma Marantaceae, sempre próximos a igarapés, com exceção de um ninho em folhas de um jambeiro (Eugenia malaccensis L.). O tamanho dos ninhos não excedia a largura da folha em que o mesmo encontravase fixado, exercendo esta uma função de proteção aos ninhos. Todos os ninhos encontravam-se numa altura de aproximadamente $1 \mathrm{~m}$, exceto o coletado no jambeiro que se encontrava a $3 \mathrm{~m}$. Ninho do tipo fragmocítaro.

Distribuição: Costa Rica, Colômbia, Venezuela, Guiana, Suriname, Guiana Francesa, Equador, Bolívia e Brasil (Amapá, Amazonas, Pará, Acre, Rondônia, Mato Grosso, Bahia, Minas Gerais, Espírito Santo e São Paulo).

Polybia dimidiata (Fig. 12) teve apenas um ninho registrado, mas não coletado, próximo à estrada de acesso à sede da Reserva Ducke. O ninho era grande, com 55 cm de com- 

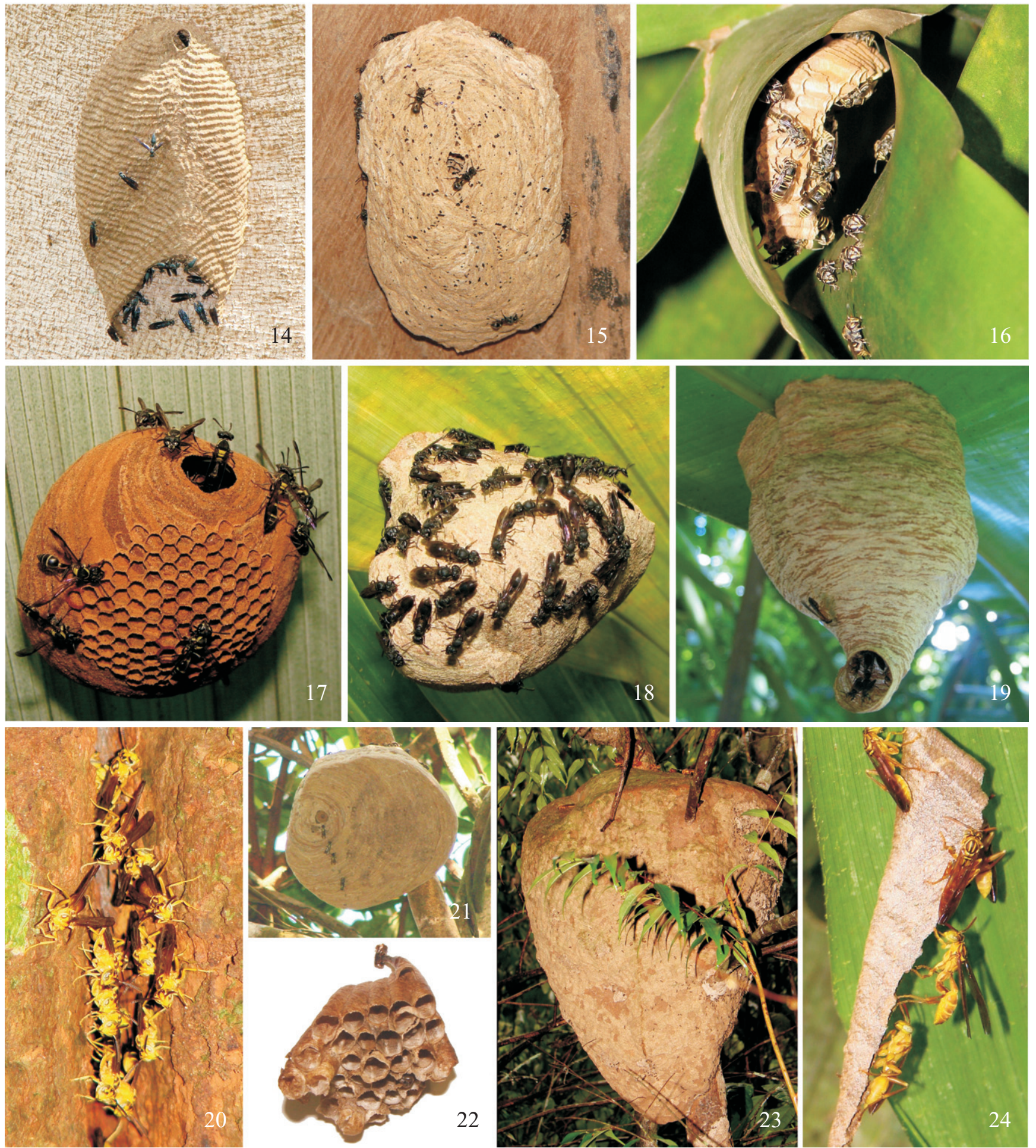

Figs. 14-24. Ninhos de: 14, Synoeca cyanea; 15, Metapolybia unilineata; 16, Protopolybia chartergoides; 17, Polybia occidentalis; 18, Polybia procellosa; 19, Angiopolybia pallens; 20, Agelaia pallipes; 21, Polybia liliacea; 22, Polistes spp.; 23, Synoeca virginea; 24, Mischocyttarus saturatus.

primento e $27 \mathrm{~cm}$ de largura, tinha uma abertura na região inferior e estava localizado próximo ao chão, há cerca de 50 $\mathrm{cm}$ de altura e circundando o tronco de uma árvore de $7 \mathrm{~cm}$ de DAP (diâmetro altura do peito). Seu interior era composto de várias camadas e uma grande quantidade de vespas, algumas em voo próximo a este e outras pousadas sobre o invólucro, principalmente próximas à abertura do mesmo. Ninho do tipo fragmocítaro.

Distribuição: Colômbia, Guiana, Suriname, Guiana Francesa, Bolívia e Brasil (Roraima, Amapá, Amazonas, Pará, Maranhão, Rondônia, Mato Grosso, Goiás, Minas Gerais, Rio de Janeiro, São Paulo e Rio Grande do Sul). 
Foram coletados dois ninhos de Polybia jurinei (Fig. 3) com dimensão de cerca de $10 \mathrm{~cm}$, com aproximadamente 200 indivíduos cada, de aspecto circular e coloração mais esbranquiçada, com aproximadamente 200 indivíduos cada. O ninho tinha duas camadas de células de cria e o invólucro era frágil e possuía apenas uma abertura na parte lateral. Um ninho foi coletado a uma altura de 8 metros, preso em um fino galho de uma árvore e o outro há $80 \mathrm{~cm}$ do solo; os ninhos tinham uma parte lateral envolta no galho para dar sustentação, não possuindo assim, pedicelo. A agressividade e a dolorosa ferroada são outras características deste grupo. Ninho do tipo fragmocítaro.

Distribuição: Colômbia, Guiana, Suriname, Guiana Francesa, Equador, Peru, Bolívia e Brasil (Amapá, Amazonas, Pará, Ceará, Acre, Rondônia, Mato Grosso, Bahia, Goiás, Minas Gerais, Espírito Santo, Rio de Janeiro e São Paulo).

Em Polybia liliacea (Fig. 21), o ninho não pôde ser coletado, mas apenas fotografado, pois estava há uma altura de 20 metros, aproximadamente. Com cerca $20 \mathrm{~cm}$ de diâmetro e de formato circular, era formado por mais de uma camada de células e fixo a um galho envolto pelo próprio ninho, possuindo apenas uma abertura, de pequena dimensão, na parte inferior do mesmo. Richards (1978) menciona que essa espécie nidifica a uma altura de 10 metros ou mais, nos ninhos que encontrou em Mato Grosso, Brasil. Ninho do tipo fragmocítaro.

Distribuição: Panamá, Colômbia, Venezuela, Guiana, Suriname, Guiana Francesa, Equador, Peru, Bolívia e Brasil (Amapá, Amazonas, Pará, Acre, Maranhão, Rondônia, Mato Grosso, Goiás e São Paulo).

Polybia occidentalis (Fig. 17) possui ninhos com dimensões pequenas a médias (entre 7 a $12 \mathrm{~cm}$ ), porém com uma grande quantidade de indivíduos (aproximadamente $200 \mathrm{em}$ média), possui um aspecto circular com invólucro frágil e apenas uma abertura na parte látero-inferior. Dois ninhos encontravam-se amplamente fixados, sem pedicelo, na face abaxial de palmeiras do gênero Astrocarium, a $1 \mathrm{~m}$ e a 1,70 $\mathrm{m}$ de altura. Um terceiro ninho foi encontrado preso a uma folha de andiroba (Carapa guianensis Aublet) a $2 \mathrm{~m}$ de altura e o outro preso a folha de jambeiro (Eugenia malaccensis L.), numa altura de aproximadamente $4 \mathrm{~m}$. O tamanho dos ninhos era inferior à largura das folhas em que os mesmos encontravam-se fixados, servindo de local seguro para a nidificação. Os ninhos possuíam de três até cinco camadas de células de cria para o depósito dos ovos. O tamanho dos ninhos não excedia a largura da folha em que o mesmo encontrava-se fixado, exercendo esta uma função de proteção aos ninhos. Uma grande quantidade de vespas encontrava-se no lado de fora do invólucro, agitadas, provavelmente sendo estas as responsáveis pela segurança do ninho. Ninho do tipo fragmocítaro.

Distribuição: Venezuela, Guiana, Suriname, Guiana Francesa, Peru, Bolívia, Paraguai, Argentina e Brasil (Roraima, Amapá, Amazonas, Pará, Maranhão, Ceará, Rio Grande do Norte, Paraíba, Pernambuco, Rondônia, Mato Grosso, Bahia, Goiás, Minas Gerais, Espírito Santo, Rio de Janeiro, São Paulo, Paraná e Rio Grande do Sul).
Dois ninhos de Polybia procellosa (Fig. 18) com dimensões pequenas (cerca de $5 \mathrm{~cm}$ ), porém com uma grande quantidade de indivíduos (aproximadamente 100 em média). Os ninhos possuem um aspecto circular, com invólucro frágil e apenas uma abertura na parte lateral e estavam amplamente fixados na face abaxial da folha de uma Marantaceae. O tamanho dos ninhos não excedia a largura da folha em que o mesmo encontrava-se fixado, exercendo esta uma função de proteção aos ninhos. Em um dos ninhos coletados próximo ao igarapé havia uma grande quantidade de cupins-soldado em seu interior, juntamente com as vespas. Esse tipo de associação ainda não foi descrito na literatura. Ninho do tipo fragmocítaro.

Distribuição: Colômbia, Guiana, Guiana Francesa, Peru, Bolívia e Brasil (Amazonas e Pará).

Polybia rejecta (Fig. 10) é uma espécie muito agressiva, algumas vezes atacando mesmo se alguém estiver a 5 ou 10 metros dos ninhos. Estes ninhos variam consideravelmente em forma, sendo normalmente subcilíndricos e amplificando-se mais abaixo, mas algumas vezes podem ser mais piriformes; todos os ninhos possuíam um tamanho entre 12 a $20 \mathrm{~cm}$. O invólucro é mais fino no topo possuindo coloração marrom ou cinza amarronzado, e os ninhos possuíam mais de uma camada de células de cria. Os seis ninhos visualizados na Reserva Ducke foram encontrados próximos a áreas antropizadas e com incidência solar maior que no interior da floresta. Dois ninhos estavam em galhos de andiroba (Carapa guianensis Aublet) e o restante em árvores de médio porte, não determinadas.

Os seis ninhos registrados desta espécie na Reserva Ducke estavam associados às colônias de formigas Azteca, algo já registrado por Richards (1978). Ninho do tipo fragmocítaro.

Distribuição: Trinidad, Panamá, Colômbia, Venezuela, Guiana, Suriname, Guiana Francesa, Peru, Bolívia e Brasil (Amapá, Amazonas, Pará, Acre, Maranhão, Rondônia, Pernambuco, Mato Grosso, Bahia, Goiás, Espírito Santo, Rio de Janeiro e São Paulo).

\section{Protopolybia Ducke, 1905}

Espécies de Protopolybia constroem seus ninhos debaixo ou entre folhas. São ninhos com um número variável de células de cria. Quando debaixo de folhas, possuem um invólucro muito frágil e geralmente de coloração esbranquiçada. Quando nidificam entre folhas, apóiam seus ninhos em uma delas e com secreção oral colam uma folha próxima no outro lado das células de cria, desta forma a própria folha da planta funciona como o invólucro. Ninhos sustentados por um pedicelo central ou vários de menor tamanho (Wenzel 1998; Carpenter \& Marques 2001).

O ninho de Protopolybia bituberculata (Fig. 11) é pequeno, com aproximadamente $6 \mathrm{~cm}$, ocupando cerca de metade da face abaxial de uma folha e fixado à mesma por vários pedicelos pequenos. O invólucro é bem frágil e possui uma coloração esbranquiçada, sendo a abertura localizada na região superior do mesmo. O ninho era formado por uma úni- 
ca camada de células de cria, de aproximadamente $1 \mathrm{~mm}$ de diâmetro e estava posicionado a $1,80 \mathrm{~m}$ de altura do solo. Ninho do tipo stelocítaro caliptódomo.

Distribuição: Brasil (Amazonas e Pará).

O ninho de Protopolybia chatergoides (Fig. 16) era pequeno, favos com aproximadamente $10 \mathrm{~cm}$, ocupando cerca de um quarto da face abaxial de uma folha de jambeiro (Eugenia malaccensis L.), a uma altura de aproximadamente $4 \mathrm{~m}$. O ninho estava apoiado em uma das folhas e com secreção oral colaram outra folha próxima no outro lado das células de cria, desta forma a própria folha da planta funciona como um invólucro. As vespas pareciam em processo de enxameamento, pois uma grande quantidade de vespas se encontrava ao redor do ninho. Ninho do tipo stelocítaro caliptódomo.

Distribuição: Brasil (Amazonas).

\section{Synoeca de Saussure, 1852}

Ninhos arbóreos, sendo que a maioria das espécies constrói suas células de cria diretamente na superfície de troncos e galhos, e as células de cria são recobertos por um invólucro com corrugações transversais. Os ninhos são compostos por fibra vegetal e possuem uma única abertura na parte superior. O invólucro geralmente é resistente e apresenta uma espessa camada de material vegetal. Em alguns casos, a parte inferior do ninho, que é a mais velha, pode ficar desabitada, enquanto os níveis superiores são ativos. Apenas Synoeca virginea nidifica contornando galhos ou árvores de pequeno diâmetro semelhante a algumas espécies de Polybia (Wenzel 1998; Carpenter \& Marques 2001).

Diferentemente dos ninhos usualmente encontrados de Synoeca, S. virginea (Fig. 23) nidifica contornando o galho ou tronco de árvores. No caso do ninho encontrado na Reserva Ducke, ficava em uma altura de $2 \mathrm{~m}$, e possuía um tamanho de $50 \mathrm{~cm}$ de comprimento por $30 \mathrm{~cm}$ de largura, com as camadas das células de cria interna e invólucro frágil, possuindo a abertura na parte superior. Alguns indivíduos ocupavam a região superior do ninho, provavelmente sendo os responsáveis pela defesa do ninho. Ninho do tipo astelocítaro.

O ninho registrado desta espécie na Reserva Ducke estava associado à colônia de formigas Azteca, algo já registrado por Richards (1978).

Distribuição: Colômbia, Guiana, Suriname, Equador, Peru, Bolívia e Brasil (Amazonas, Pará, Piauí, Acre e Mato Grosso).

\section{Mischocyttarus de Saussure, 1853}

Ninho geralmente arbóreo, podendo ser encontrado fixado em edificações humanas, e raras vezes em cavidades. Não possui o invólucro para proteção e é formado geralmente por um pedicelo fino, podendo este ser longo, resinoso, e de posição central ou lateral, geralmente constituído de fibras vegetais curtas. Os representantes deste gênero constroem ninhos pequenos (poucas dezenas de células de cria), com formato variado (de uma coluna de células de cria). Algumas espécies podem acrescentar terra na estrutura do ninho, conferindo um aspecto quebradiço. A abertura das células é considerada pequena, entre 3 a $5 \mathrm{~mm}$ de diâmetro (Wenzel 1998; Carpenter \& Marques 2001).

Mischocyttarus lecointei (Fig. 8) possuía um ninho pequeno com 11 células de cria totalmente expostas, dispostas horizontalmente e pedicelo simples e muito resistente, contendo resina. Foi coletado na face abaxial de uma folha, que cobria totalmente a área do mesmo. Foi coletado a uma altura de 2,50 m. Ninho do tipo stelocítaro gimnódomo.

Distribuição: Equador e Brasil (Amapá, Amazonas e Pará).

O ninho de Mischocyttarus saturatus (Fig. 24) possuía um ninho pequeno com 20 células de cria totalmente expostas, dispostas lateralmente e um pedicelo simples e muito resistente, contendo resina. Encontrava-se fixado na parte abaxial de uma Marantaceae, que cobria totalmente a área do mesmo. Foi coletado a uma altura de $1 \mathrm{~m}$. Ninho do tipo stelocítaro gimnódomo.

Distribuição: Equador, Peru e Brasil (Amazonas, Pará).

\section{Polistes Latreille, 1802}

Constrói ninho arbóreo, porém algumas espécies preferem locais abrigados como cavidades ou ainda em edificações humanas. Utilizam fibra vegetal na construção e o ninho não possui o invólucro para proteção. O pedicelo é curto e resinoso, podendo ser de posição central ou lateral, sendo revestido de substâncias repelentes de formigas. Os representantes deste gênero constroem ninhos pequenos (poucas dezenas de células de cria), com formato variado (de uma coluna de células cria) (Wenzel 1998; Carpenter \& Marques 2001). O ninho de Polistes (Fig. 22) foi encontrado abandonado e caído ao chão. Possuía 28 células de cria, formadas por fibras fortes e um pedicelo central resistente e resinoso. A espécie não foi determinada. Ninho do tipo stelocítaro gimnódomo.

\section{AGRADECIMENTOS}

Ao Instituto Nacional de Pesquisas da Amazônia pela oportunidade de realização da pós-graduação, a Capes pela bolsa de estudos ao primeiro autor, aos pesquisadores Fernando B. Noll, Elisabeth Franklin, Fernando Gelin e Mateus Clemente e aos revisores pelas correções e sugestões. Aos doutores James Carpenter e John Wenzel pelo envio de bibliografias.

\section{REFERÊNCIAS}

Arab, A.; T. A. O. Pietrobon; F. B. Britto; T. Rocha; L. Santos; E. F. Barbieri $\&$ H. G. Fowler. 2003. Key to the nests of Brazilian Epiponini wasps (Vespidae: Polistinae). Sociobiology 42: 425-432.

Baccaro, F. B; D. P. Drucker; J. do Vale; M. L. de Oliveira; C. Magalhães; N. Lepsch-Cunha \& W. E. Magnusson. 2008. A Reserva Ducke, p. 11-20. In: M. L. Oliveira; F. B. Baccaro; R. Braga-Neto \& W. E. Magnusson. (Eds). Reserva Ducke, a biodiversidade amazônica através de uma grade. Manaus, Instituto Nacional de Pesquisas da Amazônia, 166 p. 
Carpenter, J. M. \& O. M. Marques. 2001. Contribuição ao Estudo dos Vespídeos do Brasil. Cruz das Almas, Universidade Federal da Bahia, Série Publicações Digitais, v. 3, CD-ROM.

Jeanne, R. L. 1975. The adaptivness of social wasps nest architecture. Quarterly Review of Biology 50: 267-287.

Nascimento, F. S.; I. C. Tannure-Nascimento \& S. Mateus. 2008. Vespas Sociais Neotropicais: padrões comportamentais, regulação social e arquitetura de ninho, p. 47-67. In: E. F Vilela; I. A. dos Santos; J. H. Schoereder; J. E. Serrão; L. A. de O. Campos \& J. Lino-Neto (Eds). Insetos sociais: da biologia à aplicação. Viçosa, Editora UFV, 442 p. Prezoto, F. \& M. A. Clemente. 2010. Vespas sociais do Parque Estadual do Ibitipoca, Minas Gerais, Brasil. MG. Biota 3: 22-31.

Prezoto, F.; S. A. de O. Cortes \& A. C. Melo. 2008. Vespas: de vilãs a parceiras. Revista Ciência Hoje 43: 70-72.

Ribeiro, M. N. G. \& J. Adis. 1984. Local rainfall variability - a potential bias for bioecological studies in the Central Amazon. Acta Amazonica 14: $159-174$.

Ribeiro, J. E. L. da.; M. J. G. Hopkins; A. Vicentini; C. A. Sothers; M. A. da S. Costa; J. M. de Brito; M. A. D. de Souza; L. H. P. Martins; L. G. Lohmann; P. A. C. L. Assunção; E. da C. Pereira; C. F. de Silva; M. R. Mesquita \& L. C. Procópio. 2002. Flora da Reserva Ducke: Guia de identificação das plantas vasculares de uma floresta de terra-fir- me na Amazônia Central. Manaus, Instituto Nacional de Pesquisas da Amazônia, 816 p.

Richards, O. W. 1978. The social wasps of the Americas (excluding the Vespinae). London, British Museum of Natural History, vii $+580 \mathrm{p}$.

Richards, O. W. \& M. J. Richards. 1951. Observations on the social wasps of South America (Hymenoptera, Vespidae). Transactions of the Royal Entomological Society of London 102: 1-169.

Souza, M. M. de \& J. C. Zanuncio. 2012. Marimbondos: vespas sociais (Hymenoptera: Vespidae). Editora UFV, 79 p.

Wenzel, J. W. 1992. Behavioral homology and phylogeny. Annual Review of Ecology and Systematics 23: 361-381.

Wenzel, J. W. 1998. A generic key to the nests of hornets, yellowjackets, and paper wasps worldwide (Vespidae: Vespinae, Polistinae). American Museum Novitates 3224: 1-39.

Zanella, F. C. V; M. L. Oliveira \& M. C. Gaglianone. 2000. Standardizing lists of locality date for examined specimens in systematic and biogeography studies of new world taxa. Biogéographica 76: 145160

Zucchi, R.; S. F. Sakagami; F. B. Noll; M. R. Mechi; S. Mateus; M. V. Baio \& S. N. Shima. 1995. Agelaia vicina, a swarm-founding polistine with the largest colony size among wasps and bees (Hymenoptera: Vespidae). Journal of the New York Entomological Society 103: 129-137.

Recebido: 3/4/2012; aceito 4/11/2012

Editor: Eduardo A. B. Almeida 